\title{
Prevalence of Mantoux positivity and annual risk of infection for tuberculosis in New South Wales prisoners, 1996 and 2001
}

\author{
Michael H. Levy ${ }^{\mathrm{A}, \mathrm{B}}$, Tony G. Butler ${ }^{\mathrm{A}, \mathrm{C}, \mathrm{E}}$ \\ and Jialun Zhou $^{\mathrm{D}}$

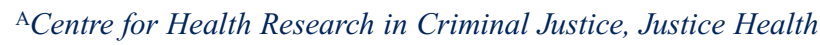 \\ ${ }^{\mathrm{B}}$ School of Public Health, University of Sydney \\ ${ }^{\mathrm{C}}$ National Drug Research Institute, Curtin University \\ of Technology \\ ${ }^{\mathrm{D}}$ National Centre in HIV Epidemiology and Clinical Research, \\ University of New South Wales \\ ECorresponding author. Email: t.butler@curtin.edu.au
}

\begin{abstract}
Objectives: This study compares the prevalence of Mantoux positivity among prisoners in NSW in 1996 and 2001 and examines factors associated with Mycobacterium tuberculosis infection. Design: Cross-sectional random samples of prisoners, including a longitudinal cohort of prisoners screened in both 1996 and 2001. Setting: 29 correctional centres. Participants: 747 men and 167 women participated in the 2001 NSW Inmate Health Survey; a cohort of 104 prisoners from the 1996 and 2001 NSW Inmate Health Surveys. Results: The prevalence of Mantoux positivity remained stable between 1996 and 2001 (12\% and 14\%, $p=0.2)$, and increased among prisoners from Asian backgrounds ( $21 \%$ and $47 \%, p=0.02)$. The annual risk of infection in the cohort among those detained continuously between 1996 and 2001 was 3.1\%, and among recidivists it was $2.7 \%(p=0.6)$. Conclusion: The risk of $M$. tuberculosis infection for Australian prisoners is assessed to be approximately four times higher than that for the community, however there is no attributable risk to the prison environment itself.
\end{abstract}

Tuberculosis is a chronic infection of Mycobacterium tuberculosis which typically occurs in two phases: (1) the initial infection, which often goes unnoticed, and (2) years later, progression to an active disease, which can be infec- tious. Infectious disease is of public health importance as transmission, via the air-borne route, is possible.

International experience has highlighted the role that prisons and prisoners play in community transmission of tuberculosis. Prisons may be important sentinel sites in which to monitor tuberculosis control at a community level. Several studies have highlighted the impact of tuberculosis within correctional centres. ${ }^{1,2}$ The high volume of prisoner movement enhances the potential for the spread of air-borne and droplet-borne illnesses within the correctional setting. ${ }^{3,4}$ There are over 9000 full-time prisoners and periodic detainees in NSW, accounting for around 180000 prisoner movements each year between correctional facilities, courthouses, community visits and hospitals.

Prisons are reported to be a risk for tuberculosis transmission independent of the predisposing risk factors of the prison population. In New York prisons, overcrowding and poor ventilation were reported as independent risk factors. ${ }^{5}$ However, these reports referred to a time and place of poor tuberculosis control in the community.

Given that prisons have many of the risk factors associated with tuberculosis transmission, eg, overcrowding, significant numbers of overseas-born individuals and frequent movement of prisoners, it is essential that this population be continually monitored. Ongoing surveillance will identify changes in the epidemiology of tuberculosis in the NSW prison system and determine changes in the annual risk of infection for the state's prisoner population.

Australia has achieved a sustained high level of tuberculosis control. The 2001 tuberculosis notification rate was 5.1 per 100000 population (being 1.0 per 100000 population for non-Aboriginal Australian born citizens). Australia had a mid-range incarceration rate of 148 prisoners per 100000 adult population in 2001. NSW houses around $35 \%$ of all prisoners in Australia.

The prison environment is implicated as a factor in the epidemiology of tuberculosis, both within the prison and in the general community. There were specific concerns regarding the transmission of tuberculosis within the NSW prison system in $1996,{ }^{6}$ which prompted the inclusion of Mantoux screening in both the 1996 and the 2001 NSW Inmate Health Surveys. ${ }^{7,8}$ 
We examined the prevalence of Mantoux positivity in two cross-sectional surveys of prisoners conducted in NSW, and estimated the annual risk of infection from tuberculosis using a prisoner cohort.

\section{Methods}

A detailed methodology for the Inmate Health Surveys has been previously described. ${ }^{9}$ The cross-sectional surveys involved screening prisoners from all 29 correctional centres in NSW. Participants were randomly selected according to sex, age and Aboriginal status. A random sample of around 10\% full-time men and 34\% full-time women prisoners across the state was taken.

Participants underwent an extensive face-to-face interview covering self-reported physical and mental health (chronic health complaints, disability, recent health complaints and symptoms and traumatic brain injury). In addition, biological samples were taken to screen for a range of infectious diseases (eg, HIV, hepatitis B and hepatitis C) and sexually transmitted infections (eg, chlamydia and gonorrhoea).

Mantoux positivity was measured as a proxy for infection with $M$. tuberculosis. A $0.1-\mathrm{mL}$ solution of purified protein derivative (PPD) (CSL Vaccines, $10 \mathrm{IU}$ ) was administered intracutaneously and the reaction was assessed after 72 hours using the ballpoint pen method. ${ }^{10}$ All prisoners in the samples were offered a Mantoux test.

According to the NSW Health Policy Directive, ${ }^{10}$ Mantoux reactions were considered to be positive if the reaction was:

- $\geq 10 \mathrm{~mm}$ in persons with no previous vaccination history, nor evidence of BCG, or

- $\geq 15 \mathrm{~mm}$ in persons with a previous BCG vaccination history.

Nurses involved in Mantoux testing were recruited from community-based tuberculosis clinics, and were accredited specifically for the performance and interpretation of the Mantoux test. Inmates who were determined to have a positive Mantoux result were recommended for specialist assessment.

The prisoner cohort involved identifying all prisoners who had participated in the 1996 Inmate Health Survey and who were also in detention at the time of the survey in 2001. The Offender Management System ${ }^{11}$ was used to locate these individuals within the NSW correctional system. The Justice Health Human Research and Ethics Committee and the Department of Corrective Services both granted ethics approval for the Inmate Health Surveys.

Assessing the rate of Mantoux positivity per annum and reporting annual risk of infection determined the inci- dence of Mantoux conversion. The International Union of Tuberculosis and Lung Disease Guidelines were used. ${ }^{12}$ The chi-square test was used as appropriate. Forward stepwise logistic regression was used to determine risk factors independently associated with Mantoux positivity. Risk factors entered into the multivariate model were: sex, age, Aboriginality, region of birth, year of survey and history of BCG vaccination. All analyses were conducted using STATA $8.2 .^{13}$

\section{Results}

Cross-sectional surveys (1996 and 2001)

A total of 789 prisoners (657 men and 132 women) were surveyed in 1996 and 914 (747 men and 167 women) in 2001. The response rate was $90 \%$ for the 1996 survey, and $85 \%$ for the 2001 survey. Mantoux tests were performed on $639(81 \%)$ prisoners in 1996 and 803 (88\%) in 2001. The median age of participants who consented to having the Mantoux test was 31 years in 1996 and 30 years in $2001(p=0.04)$. Aboriginal prisoners were younger than non-Aboriginal prisoners in each survey (28 years $v$. 33 years in 1996, $p<0.001 ; 27$ years $v .32$ years in 2001 , $p<0.001)$.

The prevalence of Mantoux positivity remained stable between $1996(12 \%)$ and $2001(14 \%)(p=0.2)$ (Table 1). However, there was an increase in the prevalence of Mantoux positivity among non-Aboriginal prisoners from $11 \%$ in 1996 to $16 \%$ in 2001 ( $p=0.04$ ) and among prisoners reporting Asian countries of birth (21\% in 1996 to $46 \%$ in $2001, p=0.02$ ).

The Mantoux prevalence was similar between the two surveys in 1996 and 2001, after adjusting for sample differences (Table 2). Risk factors independently associated with a positive Mantoux test were Aboriginal status, increasing age and birth outside Australia. In 1996, four prisoners tested positive for antibodies to HIV and one of these prisoners was Mantoux positive. In 2001, one prisoner tested positive for HIV and was Mantoux positive.

No active case of tuberculosis was detected in either crosssectional survey.

\section{Cohort (1996-2001)}

Of the 789 prisoners screened in 1996, 193 were identified as being in detention at the time of the 2001 Inmate Health Survey. Twenty-four percent (48/193) had been detained continuously between the two surveys. One hundred and eighty one $(94 \%)$ prisoners agreed to be rescreened; of these, $104(57 \%)$ received a Mantoux test regardless of their 1996 status (97 negative, seven positive in 1996). (Table 3) A total of 18 of $97(19 \%)$ participants (17 men and one woman) were Mantoux negative in 1996 and positive when retested in 2001. The calculated annual risk of infection was $3.1 \%$. None of the cohort was HIV antibody positive. 
Table 1. Prevalence of Mantoux positivity in NSW prisoners by demographic characteristics and year of survey

\begin{tabular}{|c|c|c|c|c|c|}
\hline & No. tested & $\begin{array}{l}1996 \\
\text { No. Mantoux positive (\%) }\end{array}$ & No. tested & $\begin{array}{l}2001 \\
\text { No. Mantoux positive (\%) }\end{array}$ & $p$-value \\
\hline Total & 639 & $76(12)$ & 803 & 115 (14) & 0.2 \\
\hline \multicolumn{6}{|l|}{ Sex } \\
\hline Male & 536 & $68(13)$ & 654 & $94(14)$ & 0.4 \\
\hline Female & 103 & $8(8)$ & 149 & $21(14)$ & 0.1 \\
\hline$p$-value & & 0.2 & & 0.9 & \\
\hline \multicolumn{6}{|l|}{ Age } \\
\hline$<25$ years & 185 & $9(5)$ & 247 & $17(7)$ & 0.4 \\
\hline $25-40$ years & 262 & $32(12)$ & 340 & $53(16)$ & 0.2 \\
\hline$>40$ years & 191 & $35(18)$ & 216 & $45(21)$ & 0.5 \\
\hline$p$-value & & $<0.001$ & & $<0.001$ & \\
\hline \multicolumn{6}{|l|}{ Aboriginal } \\
\hline No & 450 & $51(11)$ & 578 & $92(16)$ & 0.04 \\
\hline Yes & 189 & $25(13)$ & 225 & $23(10)$ & 0.3 \\
\hline$p$-value & & 0.5 & & 0.04 & \\
\hline \multicolumn{6}{|l|}{ Region of birth } \\
\hline Australia & 501 & $44(9)$ & 638 & $61(10)$ & 0.7 \\
\hline Oceania (other) & 23 & $3(13)$ & 41 & $5(12)$ & 0.9 \\
\hline Asia & 29 & $6(21)$ & 56 & $26(46)$ & 0.02 \\
\hline Europe & 29 & $15(52)$ & 47 & $15(32)$ & 0.09 \\
\hline Other & 18 & $4(22)$ & 17 & $7(41)$ & 0.2 \\
\hline Not reported & 39 & $4(10)$ & 4 & $1(25)$ & 0.4 \\
\hline$p$-value & & $<0.001$ & & $<0.001$ & \\
\hline \multicolumn{6}{|c|}{ Previous $B C G$ vaccination } \\
\hline No & 589 & $65(11)$ & 736 & $101(14)$ & 0.1 \\
\hline Yes & 50 & $11(22)$ & 67 & $14(21)$ & 0.9 \\
\hline$p$-value & & 0.02 & & 0.1 & \\
\hline
\end{tabular}

Source: NSW Inmate Health Surveys, 1996 and 2001

The median age among the Mantoux converters was 34 years (range 24 to 62 years). A similar rate of Mantoux conversion was found between Aboriginal and nonAboriginal participants and among participants of different ages (Table 4). Of the 18 Mantoux converters, 15 (83\%) reported being born in Australia, one in Europe, one in Asia and one had an unknown region of birth. The prevalence of Mantoux converters was similar among participants detained continuously (21\%) and among recidivists (ie, those who had spent some time in the community between surveys) $(16 \%, p=0.6)$.

\section{Discussion}

This report is the first in a randomly selected prisoner cohort and, therefore, the first report of annual risk of infection for tuberculosis in a custodial environment. These data are comparable to those of a survey of police recruits $(11 \%$ of cadets were reported to be Mantoux positive). ${ }^{14}$ Importantly, the results are higher than for community-based surveys of children, but the difference in age group is important to note. ${ }^{15,16}$
We estimate that the annual risk of infection for tuberculosis is approximately four times that for the general community. ${ }^{14,15}$ However, the risk relates to the population risks of incarcerated individuals, rather than the risk of infection within prison. The work of Dwyer et al. proposed this 10 years previously. ${ }^{17}$ Our study supports this hypothesis.

No undetected cases of active tuberculosis were identified by either survey, indicating that the risk of transmission of tuberculosis infection in the NSW prison system is low. If similar conditions existed in NSW to those found in European prisons, we could reasonably have expected to detect some active cases of tuberculosis; however, this did not eventuate.

The risk factors for Mantoux positivity have remained the same between 1996 and 2001. Certain risk factors are predictors of Mantoux positivity and should be used to prioritise screening for tuberculosis infection in Australian prisons. Birth overseas was a significant risk factor. In $2001,79 \%$ of new tuberculosis cases in Australia occurred in overseas-born persons (particularly, those from high 
Table 2. Mantoux positivity in NSW prisoners according to year of survey, demographic characteristics, and adjusted odds ratios, 1996 and 2001

\begin{tabular}{|c|c|c|c|c|c|c|}
\hline & No. tested & $\begin{array}{l}\text { No. Mantoux } \\
\text { positive (\%) }\end{array}$ & $p$-value & Adjusted OR & $95 \% \mathrm{Cl}$ & $p$-value \\
\hline Total & 1442 & $191(13)$ & & & & \\
\hline \multicolumn{7}{|l|}{ Year of survey } \\
\hline 1996 & 639 & $76(12)$ & & 1.0 & & \\
\hline 2001 & 803 & $115(14)$ & 0.2 & 1.2 & $0.9-1.7$ & 0.3 \\
\hline \multicolumn{7}{|l|}{ Sex } \\
\hline Male & 1190 & $162(14)$ & & 1.0 & & \\
\hline Female & 252 & $29(12)$ & 0.4 & 0.7 & $0.5-1.1$ & 0.2 \\
\hline \multicolumn{7}{|l|}{ Age } \\
\hline$<25$ years & 432 & $26(6)$ & & 1.0 & & \\
\hline $25-40$ years & 602 & $85(14)$ & & 2.9 & $1.8-4.6$ & $<0.001$ \\
\hline$>40$ years & 407 & $80(20)$ & $<0.001$ & 3.8 & $2.3-6.2$ & $<0.001$ \\
\hline \multicolumn{7}{|l|}{ Aboriginal } \\
\hline No & 1028 & $143(14)$ & & 1.0 & & \\
\hline Yes & 414 & $48(12)$ & 0.2 & 1.6 & $1.0-2.3$ & 0.03 \\
\hline \multicolumn{7}{|l|}{ Region of birth } \\
\hline Australia & 1139 & $105(9)$ & & 1.0 & & \\
\hline Oceania (other) & 64 & $8(13)$ & & 2.0 & $0.9-4.5$ & 0.09 \\
\hline Asia & 85 & $32(38)$ & & 8.3 & $4.9-14.1$ & $<0.001$ \\
\hline Europe & 76 & $30(39)$ & & 6.0 & $3.4-10.4$ & $<0.001$ \\
\hline Other & 35 & $11(31)$ & & 5.0 & $2.3-10.9$ & $<0.001$ \\
\hline Not reported & 43 & $5(12)$ & $<0.001$ & - & - & - \\
\hline \multicolumn{7}{|c|}{ Previous $B C G$ vaccination } \\
\hline No & 1325 & $166(13)$ & & 1.0 & & \\
\hline Yes & 117 & $25(21)$ & 0.007 & 1.0 & $0.6-1.8$ & 0.9 \\
\hline
\end{tabular}

prevalence countries such as Vietnam, China, the Philippines, India and Indonesia). ${ }^{18}$ Among the Australian-born participants, $21 \%$ of new cases were reported as being Aboriginal, ${ }^{18}$ a group who are significantly overrepresented in NSW prisons $(1.4 \%$ of the general population but approximately $20 \%$ of the NSW prisoner population). ${ }^{19}$

This study experienced logistical problems associated with conducting Mantoux screening in prisons, with a number of prisoners unavailable for follow-up skin test readings and for chest $\mathrm{x}$-rays. This inability to follow-up prisoners was primarily due to release from gaol or internal loss due

Table 3. Mantoux test results among NSW prisoners who participated in the 1996 and 2001 Inmate Health Surveys

\begin{tabular}{l|rcr}
\hline Mantoux test 1996 & \multicolumn{3}{|c}{ Mantoux test 2001 } \\
& Negative & Positive & Total \\
\hline Negative & 79 & 18 & 97 \\
Positive & 2 & 5 & 7 \\
Total & 81 & 23 & 104 \\
\hline
\end{tabular}

to transfers within the prison system. Some prisoners were unable to attend local chest x-ray clinics or hospitals for security reasons. These issues have been highlighted in a previous report. ${ }^{3}$ Further research is required to assess the management of the Mantoux converters.

Mantoux conversion occurs when a person with a previously negative Mantoux test result shows a positive result, indicating that the person has become exposed to M. tuberculosis. By definition, it is an incident case of infection, but not an incident case of disease (a diagnosis dependent on sputum examination, x-ray and clinical signs and symptoms). Importantly, recently infected individuals are rarely infectious themselves, ie, they do not excrete organisms into the environment. We identified 10 continuously detained Mantoux converters, suggesting that infection occurred while the custodial authority had a 'duty of care' for the individual. It does not indicate at which time or place the conversion occurred.

There have been numerous reports of prison-to-community spread of tuberculosis. ${ }^{17,20}$ We were concerned about an undetected ongoing micro-epidemic in the prison 
Table 4. Demographic characteristics of Mantoux converters among NSW prisoners who participated in the 1996 and 2001 Inmate Health Surveys

\begin{tabular}{lccc}
\hline & $\begin{array}{c}\text { No. } \\
\text { participants }\end{array}$ & $\begin{array}{c}\text { No. Mantoux } \\
\text { conversion (\%) }\end{array}$ & p-value \\
\hline $\begin{array}{l}\text { Total } \\
\text { Sex }\end{array}$ & 97 & $18(19)$ & \\
$\quad$ Male & 86 & $17(20)$ & 0.4 \\
$\quad$ Female & 11 & $1(9)$ & \\
Age (in 2001) & & $7(17)$ & 0.9 \\
$<25$ years & 41 & $7(21)$ & \\
$25-40$ years & 33 & $4(17)$ & 0.9 \\
$>40$ years & 23 & $14(19)$ & \\
Aboriginal & & $4(18)$ & \\
No & 75 & $15(18)$ & \\
Yes & 22 & $0(0)$ & 0.7 \\
Region of birth & & $1(33)$ & \\
Australia & 81 & $1(33)$ & \\
Oceania (other) & 3 & $0(0)$ & \\
Asia & 3 & $10(21)$ & \\
Europe & 3 & $8(16)$ & \\
Other & 4 & & \\
Not reported & 3 & & \\
Continuous imprisonment & 48 & & \\
Yes & & & \\
No & 49 & & \\
\hline
\end{tabular}

system, as evidenced by the Mantoux conversions among the 1996-2001 cohort. However, we were unable to identify a point-source of infection due to the nature of the study, a population-based cross-sectional survey.

It is notable that there was no difference in annual risk of infection between recidivists and those continuously incarcerated. This situation indicates that the risk of exposure to $M$. tuberculosis is related to the antecedents of incarceration and not to the prison environment itself. This hypothesis may only be applicable to low prevalence environments for both tuberculosis and HIV. The contrary position has been proposed in a high tuberculosis prevalence environment, where distinct risks for community and prison are reported. ${ }^{21}$

Importantly, the higher prevalence of tuberculosis infection among prisoners was similar in the two subgroups within the cohort - those continuously incarcerated and those who had spent some of the intervening period in the community. We were unable to attribute a specific risk of tuberculosis infection to incarceration, rather the risk may be common to that subsection of the general population who are prisoners. This situation is in distinct contrast to the situation with hepatitis $\mathrm{C}$ and Australian prisons. $^{22}$ In low-tuberculosis-incidence countries like Australia, prisons are not a reservoir of infection but a temporary repository of people with higher exposure to tuberculosis.

Despite improvements in the delivery of health services to prisoners and better surveillance capacity, the imprecision of the diagnosis of tuberculosis infection and the substantial risk of false-positive results in a low prevalence population precludes against recommending routine Mantoux screening for NSW prisoners. The hallmark of tuberculosis control will remain rapid identification of active disease, with prompt isolation of tuberculosis suspects. Sputum microscopy remains the 'gold standard' for diagnosis as the assessment of public health risk is critical in mounting a response to tuberculosis in a low-prevalence country.

Justice Health and the Department of Corrective Services now have an effective referral process to the negative pressure cells at the Long Bay Hospital, based on the principles of early referral, infection control and secure and safe transportation. The link between the governance structure of prisoner health and the potential benefits to public health, have been proposed in the context of tuberculosis. ${ }^{23}$ NSW prisoners are provided with health care directly from community health funds through an independent health authority, Justice Health NSW. This position is consistent with that proposed by Baroness Stern: ${ }^{23}$ 
'Restructuring the prison medical service so that it is part of the national health system has been regarded as a prerequisite of the protection of prisoners' rights.'

While the risk of tuberculosis transmission in the NSW prison system is currently considered to be low, prisoners can be sentinels for community based tuberculosis control programs. With good control programs in the community and proper governance of prisoner health services, the public health is well served. In low-prevalence situations, prisoners can be protected, and prisons may not pose added health risk to the community. This has been the Australian experience with HIV. ${ }^{24}$ So too with tuberculosis.

\section{References}

1. MacIntyre CR, Carnie J, Randall M. Risk of transmission of tuberculosis among prisoners of an Australian prison. Epidemiol Infect 1999; 123: 445-50. doi:10.1017/S095026889900312X

2. Reichard AA, Lobato MN, Roberts CA, Bazerman LB, Hammett TM. Assessment of tuberculosis screening and management practices of large jail systems. Pub Health Rep 2003; 118: 500-7.

3. Levy MH, Quilty S, Young LC, Hunt W, Matthews R, Robertson PW. Pox in the docks: varicella outbreak in an Australian prison system. Public Health 2003; 117: 446-51. doi:10.1016/S0033-3506(03)00138-0

4. Levy MH, Gater C. The cough that packed a punch: is boxing a risk for tuberculosis transmission? Med J Aust 2000; 173: 671.

5. Bellin EY, Fletcher DD, Safyer SM. Association of tuberculin infection with increased time or admission to the New York jail system. JAMA 1993; 269: 2228-31. doi:10.1001/jama.269.17.2228

6. Conaty S, Christiansen A, Butler T, McCauley J, Goldberg H. Tuberculosis in NSW correctional centres: disease control measures following infectious cases. N SW Public Health Bull 1996; 7: 138-9.

7. Butler T. Preliminary findings of the NSW Inmate Health Survey. Sydney: NSW Corrections Health Service, 1997.

8. Butler T, Milner L. The 2001 Inmate Health Survey. Sydney: NSW Corrections Health Service, 2003.

9. Butler T, Levy M. Mantoux positivity among prison prisoners - New South Wales, 1996. Aust N Z J Public Health 1999; 23: $185-8$.

10. NSW Department of Health. Tuberculin skin testing. Policy Directive. PD2005_580. Sydney: NSW Department of Health, 2005.
11. The Offender Management System. Electronic database. Sydney: Department of Corrective Services.

12. Bleiker MA, Sutherland I, Styblo K, ten Dam HG, Misljenovic O. Guidelines for estimating the risks of tuberculosis infection from tuberculin test results in a representative sample of children. Bull Int Union Tuberc Lung Dis 1989; 64: 7-12.

13. STATA 8.2 for Windows [statistical package]. College Station, TX: StataCorp, 2005

14. Coolahan LM, Levy MH. The prevalence of tuberculosis infection in New South Wales police recruits, 1987-1990. Med J Aust 1993; 159: 369-72.

15. Alperstein G, Fett MJ, Reznik R, Thomas M, Senthil M. The prevalence of tuberculosis infection among Year 8 schoolchildren in 1992. Med J Aust 1994; 160: 197-201.

16. Alperstein G, Morgan KR, Fett MJ, Nossar V, Stewart GJ. Prevalence of tuberculosis infection among primary schoolentry children. Aust NZ J Pub Health 1996; : 123-8.

17. Dwyer B, Jackson K, Raios K, Sievers A, Wilshire E, Ross B. DNA restriction fragment analysis to define an extended cluster of tuberculosis in homeless men and their associates. J Infect Dis 1993; 167: 490-4.

18. Miller M, Lin M, Spencer J, Antic R, Bastion I, Christensen A et al. Tuberculosis notifications in Australia, 2001. Commun Dis Intell 2002; 26: 525-36.

19. Australian Bureau of Statistics. Prisoners of Australia 2006. Cat. no. 4517.0. Canberra: Australian Bureau of Statistics, 2006.

20. Stead WW. Undetected tuberculosis in prison. Source of infection for community at large. JAMA 1978; 240: 2544-7. doi:10.1001/jama.240.23.2544

21. Kimerling ME, Slavuckij A, Chavers S et al. The risk of MDRTB and polyresistant tuberculosis among the civilian population of Tomsk city, Siberia 1999. Int J Tuberc Lung Dis 2003; 7: 866-72.

22. van Beek I, Dwyer R, Dore GJ, Luo K, Kaldor JM. Infection with HIV and hepatitis $\mathrm{C}$ virus among injecting drug users in a prevention setting: retrospective cohort study. BMJ 1998; 317: 433-7.

23. Stern V. Prison reform and public health. The case of tuberculosis in the former Soviet Union. Eur J Public Health 2000; 10: 4. doi:10.1093/eurpub/10.1.4

24. McDonald AM, Ryan JW, Brown PR, Manners CJ, Falconer AD, Kinnear RC et al. HIV prevalence at reception into Australian prisons, 1991-1997. Med J Aust 1999; 171: $18-21$. 